\title{
Characteristics Of Patients Underwent Percutaneous Endoscopic Lumbar Discectomy In Medan
}

\author{
Rudy Tanudin ${ }^{1}$, Pranajaya Dharma Kadar ${ }^{2}$, Benny $^{3}$ \\ ${ }^{1}$ Orthopaedic dan Traumatology resident, Sumatera Utara University, Faculty of Medicine/ RSUP Haji Adam \\ Malik -Medan \\ ${ }^{2}$ Orthopaedic danTraumatology Consultant, Sumatera Utara University, Faculty of Medicine/ RSUP Haji Adam \\ Malik -Medan \\ ${ }^{2}$ Orthopaedic danTraumatology Consultant, Sumatera Utara University, Faculty of Medicine/ RSUP Haji Adam \\ Malik -Medan
}

\begin{abstract}
Objective

Percutaneous Endoscopic Lumbar Discectomy (PELD) is a modern minimally invasive surgical technique used mainly to remove lumbar disc and has several advantages over open discectomy or microdiscectomy techniques. The purpose of this research is to identifythe characterictics of Herniated Nucleus Pulposus (HNP) patients treated with PELD.
\end{abstract}

\section{Material dan Methods}

This is a retrospective descriptive research with a cross sectional design held in Medan, Indonesia from June 2019 up until December 2020. Sample was obtained using total sampling method from the medical records of patients diagnosed with HNP undergoing PELD surgery. The information obtained would include the patient's demographic information, length of stay, intraoperative bleeding, duration of operation, HNP type, and HNP location. The data obtained would then be analized and presented through a table and description.

\section{Result}

A total of 7 patients was obtained, 1 male (14.3\%) and 6 female (85.7\%) The sample's mean age is $47.86 \pm 17.325$ years old with a range between 20 and 68 years old, the median age is 55 years old. The sample's mean body weight is $61.43 \pm 3.952 \mathrm{~kg}$, mean operation duration is $2.29 \pm 1.254$ hours, length of stay is $3.00 \pm 0.816$ days, dan intraoperative bleeding is $328.57 \pm 111.270 \mathrm{ml}$. The type of HNP observed is buldging (72\%), extruded (14\%), and prolapsed (14\%). Most HNP occurs at L5-S1 (50\%), while at L4-L5 and L3-4 occurrence is 33\% and $17 \%$ respectively.

\section{Conclusion}

Through the data obtained, it can be concluded that PELD is a minimally invasive surgery, efective for patients of all ages which causes minimal intraoperative bleeding and has shorter operation and post-operative hospital length of stay compared to other surgical methods. PELD can and should be acknowledged to be a good surgical intervention for HNP patients.

\section{Keyword}

PELD, HNP, Surgery, Minimally invasive, Vertebrae 


\section{Background}

Herniated Nucleus Pulposus (HNP) or herniated intervertebral disc is a common disorder which occurs more commonly in the adult population due to degenerative changes of the vertebrae (Do-Keun et al, 2011). HNP incidence in most developing countries is $15-20 \%$ of total population, but mainly affects people aged 30-50 years old with the peak incidence between 40-45 years old. It occurs more commonly in male with a 2:1 ratio. It most frequently occurs at the lumbal region of the vertebrae with a little percentage occuring at the cervical region and even less (1:1.000.000) occuring at the thorax region. In patients between 25-55 years old, 95\% of HNP of the lumbar region occurs between L4-L5 or L5-S1, while HNP above L4 is more commonly found in people older than 55 years old (Jordan, Konstantinou, O’Dowd, 2009).

HNP can be managed conservatively or through surgical means. Conservative management of HNP includes injection for pain management, traditional therapy such as; herbal, acupuncture, bee venom pharmacopuncutre, or spinal manipulation, and physical therapy. Surgical management include microdiscectomy, open discectomy, as well as minimally invasive surgery such as Percutaneous Endoscopic Lumbar Discectomy (PELD) (Amin, Andrade, Neuman, 2017).

Surgical management is indicated if conservative management fails after 6 weeks of pain management and pain reoccurs or persists. Minimally invasive surgery has grown in popularity for vertebral surgery in the past 15 years and PELD is currently the most modern surgical technique for lumbar herniated discs. PELD has several advantages compared to other surgical techniques such as open dicectomy or microdiscectomy, because it doesn't require lamina or facet joint removal which is crucial for spinal stability. It also causes less damage towards surrounding muscles and ligaments which shortens the patient's rehabilitation duration and length of stay. PELD has two approaches, which is transforaminal and interlaminar approach (Peng Chan, Yeo, Tan Seang, 2009).

A proper research to determine patient's characteristic fit for PELD surgery hasn't been done in Asia, more precisely in Medan, Indonesia. For that reason, this research is done to identify HNP characteristics suited for PELD surgery for patients in Medan.

\section{Materials and Method}

This is a retrospective descriptive research with a cross sectional design. Sample was obtained using total sampling method from the medical records of patients diagnosed with HNP undergoing PELD surgery. The information would include the patient's demographic information, length of stay, intraoperation bleeding, operation duration, HNP type, and HNP location. The data obtained would then be analized and presented through table and description.

The research is held on Royal Prima Hospital, Sumatera Utara, Medan, from June 2019 - September 2020. The target population is every patient who is diagnosed with HNP in Medan who is treated with PELD in Royal Prima Hospital. The sampel used for this research is every patient meeting the inclusion and exclusion criteria. The inclusion criteria for this research is every patient who has been diagnosed with HNP, managed by PELD. The exclusion criteria is patients who is or has had other back surgeries other than PELD.

Data obtained is then analized using SPSS version 25.0 and is then shown in a descriptive fashion. Every data obtained is then described and presented in tables.

\section{Result}

Total samples obtained was 7 samples, 1 male (14.3\%) and 6 female $(85.7 \%)$. The mean age of the sample is 47.86 years old with a range between $20-68$ years old and the median age is 55 years old. The demographic characteristics of samples who underwent PELD surgery is shown below (table 1). 
Table 1. Characteristics of patient

\begin{tabular}{lll}
\hline Characteristics & n & \% \\
\hline Sex & & \\
Male & 1 & 14.3 \\
Female & 6 & 85.7 \\
& & \\
\hline & Mean & SD \pm \\
\hline Age & 47.86 & 17.325 \\
Weight & 61.43 & 3.952 \\
Surgery duration & 2.29 & 1.254 \\
Length of Stay & 3.00 & 0.816 \\
Bleeding & 328.57 & 111.270 \\
\hline HNP & $\mathbf{n}$ & $\%$ \\
\hline Type & & \\
\hline Buldging & 5 & 72 \\
Extruded & 1 & 14 \\
Prolapse & 1 & 14 \\
Sequestered & 0 & 0 \\
\hline Level & & \\
\hline L5 - S1 & 4 & 50 \\
L4 - L5 & 2 & 33 \\
L3 - L4 & 1 & 17 \\
& &
\end{tabular}

The sample has a mean age of $47.86 \pm 17.325$ years old with a range between $20-68$ years old and a median age of 55 years old. The mean body weight is $61.43 \pm 3.952 \mathrm{~kg}$, surgery duration is $2.29 \pm 1.254$ hours, length of stay is $3.00 \pm 0.816$ days, and intraoperative bleeding is $328.57 \pm 111.270 \mathrm{ml}$. The most common type of HNP is bulging $72 \%$ ( 5 subjects), followed by prolapse 14\% (1 subject) dan extruded 14\% (1 subject). HNP is most commonly found between L5-S1 50\% (3 subjects), followed by L4-L5 33\% (2 subjects) and L3-L4 17\% (2 subjects).

\section{Discussion}

Almost $80 \%$ of all population will experience low back pain at least once in their lives (Anderson, G.B., 1999). The most common cause of low back pain is intervertebral degeneration which causes HNP (Martin, Deyo, Mirza, 2008).

Percutaneous Endoscopic Discectomy (PED) is a minimally invasive surgery, effective for the management of HNP and has a low risk of complications (inadequate disc removal $1.4 \%$, HNP recurrence $2.8 \%$, nerve root injury $1.2 \%$, tear of the dura $0.9 \%$, post-operative pain $2.3 \%$ ) due to its minimally invasive nature and it causes little trauma to the surrounding muscles and ligaments. (Zhou et al, 2018). With a success rate of $98.1 \%$ according to endoscopic criteria, PELD can be considered to be an ideal alternative management for complex herniated disc cases (Kim et al, 2018).

Similar research of the same nature showed an average surgery duration between $41.3-45.8$ minutes with little-to-no intraoperative bleeding and a mean length of stay post surgery between $2.8-3$ days. Prolonged length of stay occurs when patients present with disesthesia, neurologic deficit, headache, nausea, or due to lengthy distance between home and hospital (Cao et al, 2019). Another research held in Nanjing, China, on 2018, evaluating 77 patients diagnosed with HNP with a mean age of 68.33 years old undergoing PELD surgery showed that the mean surgery duration to be 87.31 minutes and a mean post-operative hospital of 3.79 days. It is concluded that according to McNab Criteria, the result of the operation is good (76.1\%), fair (10\%), and poor (6\%) (Singh, Xin, Hirachan, et al, 2018).

A research held in India on 2018, consisting of 614 patients undergoing PELD surgery, it is found that the mean surgery duration is 45 minutes, intraoperative bleeding is $65 \mathrm{~mL}$, and postoperative in-hospital care is 16.2 hours. (Dey \& Nanda, 2019) 
A meta-analysis consisting of 7 scientific paper in Korea on 2018 compared PELD and open discectomy. The paper concluded that patients undergoing PELD procedure has a shorter operation duration and a shorter post operative duration. (Kim et al, 2018).

A reseach held in Beijing on 2020 found a significant difference of surgical duration, intraoperative bleeding and post-operative length of stay between patients undergoing PELD and open discectomy. Patients who underwent PELD surgery has an average operative duration of 94.5 minutes, while open discectomy surgery reuired 148 minutes. The amount of intraoperative bleeding patients undergoing PELD surgery is $18.1 \mathrm{~mL}$, while patients undergoing open discectomy had an average amount of bleeding of $308.6 \mathrm{ml}$. The lentgth of stay of patients following open discetomy is also twice as long, compared to patients undergoing PELD, 7.7 days and 3.5 days respectively. (Li et al, 2020).

A meta-analysis consisting of 9 research papers in China on 2018 showed that there is no significant difference between PELD and open discectomy in terms of operation duration. However open micodiscectomy approach showed a significant difference in terms of post operative length of stay and rehabilitation duration. (Qin et al, 2018)/

Another research held in 2018 with the average sample age of 15.4 years old showed that surgery duration of patients undergoing PELD is 80.9 minutes with a post-operative length of stay of 5.8 days. (Xu, Liu, Chen et $a l, 2018)$.

A meta-analysis consisting of 7 researches in China on 2016 comparing PELD and open discectomy showed that the length of operation of PELD and open discectmy is 42 minutes and 47.37 minutes respectively, intraoperative bleeding is $6.65 \mathrm{~mL}$ and $72 \mathrm{~mL}$ respectively, and postoperative length of stay to be 1.9 days and 5.6 days respectively. On all 3 aspects it showed a significant difference. (Li et al, 2016).

Another paper held in Korea on 2016 showed a significant difference of operation duration, postoperative length of stay, and rehabilitation period between PELD and open microdiscetomy. It is concluded that PELD is an effective method of surgery for HNP. (Choi, Kim, Park, 2016).

In this research, a difference was found in compared to other researches, because PELD requires a significant learning curve with a failure rate of $7.8 \%$ and a complication rate of 3.9\%. (Lee, Lee, 2008) The operator has to have a significant set of skill and experience, which is an important factor in the success of PELD. (Wang, Huang, Li et al, 2013).

\section{Conclusion}

In conclusion, PELD is a minimally invasive surgery which is effective for patients of all ages. It has several advantages in compared to other more traditional operation methods, as it may require a shorter surgery duration and a surgery post-operative length of stay. Therefore PELD is suitable as an alternative surgery management for HNP.

\section{References:}

Amin, R.M., Andrade N.S., Neuman B.J. 2017. Lumbar Disc Herniation. Curr Rev Musculoskelet Med; 10: 507516.

Cao, J., Wu, T., Jia, J., Cheng, X. 2019. Percutaneous Endoscopic Lumbar Discectomy for Lumbar Disc Herniation as Day Surgery - Short Term Clinical Result of 235 Consecutive Cases. Medicine 98: 49

Choi, K., Kim, J., Park, C., 2016. Percutaneous Endoscopic Lumbar Discectomy as an Alternative to Open Lumbar Microdiscectomy for Large Lumbar Disc Herniation. Pain Physician; 19: E291-300

Dey, P.C., Nanda, S.N., 2019. Functional Outcome after Endoscopic Lumbar Discectomy by Destandau's Technique: A Prospective Study of 614 Patients. Asian Spine J;13(S);786-792

Jordan, J., Konstantinou, K., O’Dowd, J. 2009. Herniated Lumbar Disc. Clinical Evidence. 2009; 03:1118.

Kim, M., Lee, S., Kim, H., Park, S., Shim, S., Lim, D. 2018. A Comparison of Percutaneous Endoscopic Lumbar Discectomy and Open Lumbar Microdiscectomy for Lumbar Disc Herniation in the Korean: A MetaAnalysis. BioMed Research International

Lee, D.Y., Lee, S., 2008. Learning Curve fot Percutaneous Endoscopic Lumbar Discectomy. Neurol Med Chir (Tokyo); 48: 383-389

Li, X., Han, Y., Di, Z., Cui, J., Pan, J., Yang, M., et al. 2016. Percutaneous Endoscopic Lumbar Discectomy for Lumbar Disc Herniation. J Clin Neurosci (2016) 
Li, Z., Zhang, C., Chen, W., Li, S., Yu, B., Zhao, H., et al. 2020. Percutaneous Endoscopic Transforaminal Discectomy versus Conventional Open Lumbar Discectomy for Upper Lumbar Disc Herniation: A Comparative Cohort Study. BioMed Research International

Martin, B.I., Deyo, R.A., Mirza, S.K. 2008. Expenditures and Health Status among Adults with Back and Neck Problem. JAMA; 299(6):656

Peng Chan, W.B., Yeo, W., Tan Seang, B. 2009. Percutaneous Endoscopic Lumbar Discectomy: Clinical and Quality of Life Outcomes with a Minimum 2 Year Follow-up. Journal of Orthopaedic Surgery and Research; 4:20.

Qin, R., Liu, B., Hao, J., Zhou, P., Yao, Y., Zhang, F., Chen, X. 2018. Percutaneous Endoscopic Lumbar Discectomy versus Posterior Open Lumbar Discectomy for the Treatment of Symptomatic Lumbar Disc Herniation: A Systematic Review and Meta-Analysis. World Neurosurg; 120:352-362

Singh, R., Xin, G.Z., Hirachan, M.P., Cheng, L.Y. 2018. Outcome of Percutaneous Transforaminal Endoscopic Lumbar Surgery in >60-Year-Old Patients with Low Back Pain. Asian Spine J;12(3);511-517

Wang, H., Huang, B., Li, C., Zhang, Z., Wang, J., et al. 2013. Learning Curve for Percutaneous Endoscopic Lumbar Discectomy depending on the Surgeon Training Level of Minimally Invasive Spine Surgery. Clin Neurol Neurosurg; 115(10)

Xu, Z., Liu, Y., Chen, J., 2018. Percutaneous Endoscopic Interlaminar Discectomy for Adolescent Lumbar Disc Herniation. Turk Neurosurg; 28(6): 923-928

Zhou, C., Zhang, G., Panchal, R., Ren, X., Xiang, H., Xuexiao, M., et al. 2018. Unique Complication of Percutaneous Endoscopic Lumbar Discectomy and Percutaneous Endoscopic Interlaminar Discectomy. Pain Physician; 21; E105-E112 